\title{
Hand-Portable Gas Chromatograph-Toroidal Ion Trap Mass Spectrometer (GC-TMS) for Detection of Hazardous Compounds
}

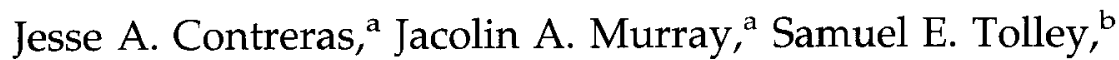 \\ Joseph L. Oliphant, ${ }^{b}$ H. Dennis Tolley, ${ }^{a}$ Stephen A. Lammert, ${ }^{\text {a* }}$ \\ Edgar D. Lee, ${ }^{b}$ Douglas W. Later, ${ }^{b}$ and Milton L. Lee ${ }^{a}$ \\ a Department of Chemistry and Biochemistry, Brigham Young University, Provo, Utah, USA \\ b Torion Technologies, American Fork, Utah, USA
}

A novel gas chromatograph-mass spectrometer (GC-MS) based on a miniature toroidal ion trap mass analyzer (TMS) and a low thermal mass GC is described. The TMS system has an effective mass/charge $(\mathrm{m} / \mathrm{z})$ range of 50-442 with mass resolution at full-width half-maximum (FWHM) of 0.55 at $\mathrm{m} / \mathrm{z} 91$ and 0.80 at $\mathrm{m} / \mathrm{z} 222$. A solid-phase microextraction (SPME) fiber mounted in a simple syringe-style holder is used for sample collection and introduction into a specially designed low thermal mass GC injection port. This portable GC-TMS system weighs $<13 \mathrm{~kg}(28 \mathrm{lb})$, including batteries and helium carrier gas cartridge, and is totally self-contained within dimensions of $47 \times 36 \times 18 \mathrm{~cm}(18.5 \times 14 \times 7$ in.). System start-up takes about $3 \mathrm{~min}$ and sample analysis with library matching typically takes about $5 \mathrm{~min}$, including time for column cool-down. Peak power consumption during sample analysis is about $80 \mathrm{~W}$. Battery power and helium supply cartridges allow 50 and 100 consecutive analyses, respectively. Both can be easily replaced. An on-board library of target analytes is used to provide detection and identification of chemical compounds based on their characteristic retention times and mass spectra. The GC-TMS can detect $200 \mathrm{pg}$ of methyl salicylate on-column. $n$-Butylbenzene and naphthalene can be detected at a concentration of $100 \mathrm{ppt}$ in water from solid-phase microextraction (SPME) analysis of the headspace. The GC-TMS system has been designed to easily make measurements in a variety of complex and harsh environments. (J Am Soc Mass Spectrom 2008, 19, 1425-1434) @ 2008 American Society for Mass Spectrometry

$\mathrm{W}$ hen exposure to hazardous compounds, such as chemical warfare agents (CWAs) and toxic industrial chemicals (TICs), is a concern, the ability to rapidly detect and accurately identify such chemicals in harsh environments is of great utility. There is a need for field-portable, selective, and sensitive detectors for military and emergency first-responder operations and for on-site environmental contamination measurement, to mention only a couple of key applications. The development of fieldportable devices directed toward fast, on-site analysis is one of the most active research areas in analytical chemistry.

Currently, several approaches for detection of CWAs and TICs are utilized by military personnel, first responders, and environmental scientists. They include dye solubility (detection paper), enzymatic reaction,

Address reprint requests to Dr. Milton L. Lee, Brigham Young University, Department of Chemistry and Biochemistry, Cro0 Benson Science Building, Provo, UT 84602-5700. E-mail: mllee@chem.byu.edu.

* Stephen A. Lammert is an adjunct research scientist at Brigham Young University. gas-solid-phase reaction, surface acoustic wave (SAW), flame photometry (FPD), and ion mobility spectrometry (IMS) [1-4]. These detectors, although small and relatively easy to use in the field, offer only limited chemical specificity and sensitivity, and they are prone to false-positive responses [3]. They typically can confirm only what is already believed to be present, but cannot provide information about other possible harmful agents $[1,5]$.

Combining results obtained from several individual analytical techniques has been shown to be particularly advantageous for detection of possible chemical threats [6]. MS alone can be used to identify unknown compounds from their characteristic fragmentation patterns; however, for complex mixtures, compound identification by MS alone can be challenging. MS coupled with a separation technique such as gas chromatography $(\mathrm{GC})$ can provide two-dimensional analysis, which provides significantly greater power for identification of compounds in complex mixtures. Analytical advantages of high sensitivity, high selectivity, and rapid response time make GC-MS a preferred detection tech- 
nique for CWAs and TICs [7]. GC-MS remains the standard for positive identification of unknown volatile and semi-volatile organic compounds, and the preferred instrumentation for field detection and verification of chemical agents $[1,8,9]$.

Major efforts have been made to miniaturize capillary GC [10-14] and most MS analyzers, including time-of-flight (TOF) [15-17], quadrupole [18], magnetic sector [17-19], Fourier transform ion cyclotron resonance (FTICR) [20], and cylindrical [21-23], rectilinear [24-26], and toroidal [27, 28] ion traps. Most of these reports have concentrated on miniaturizing the GC column or the mass analyzer. However, few groups have focused on miniaturizing other system components such as vacuum pumps, electronics, and consumable items required for truly portable (i.e., totally selfcontained) GC-MS systems [19, 24, 29, 30]. Even so, a number of so-called portable systems have been commercialized [9, 24, 29-37]. The most widely used portable GC-MS system by military and first-responder personnel, for example, suffers from several limitations: the analysis time for a sample is about $15 \mathrm{~min}[32,36]$, which is quite slow for field applications that require immediate response; the use of a membrane sample inlet limits the range of analytes that can be introduced into the system [38]; the getter vacuum pump in this system has a finite lifetime (30 days at $8 \mathrm{~h} /$ day operation) and must be replaced at the manufacturer's facility; and field-portability requires taking along the support platform, which weighs about as much as the GC-MS system.

The high demand for portable GC-MS is driving further efforts to develop systems that are even smaller and more rugged, with the goal of producing a truly hand-portable GC-MS system. Among the different types of mass analyzers, ion traps are ideal candidates for miniaturization because of their simplicity, high sensitivity, relatively high operating pressure, and less stringent ion optic element alignment compared with other types of MS analyzers [39]. Furthermore, ion traps provide potential for tandem MS operation in a portable MS format. Lower power consumption can be achieved by reducing the trapping volume radial dimension. One limitation to miniaturizing ion traps is reduction in ion storage capacity. However, this reduction can be ameliorated by trapping ions in a toroidal geometry $[27,28,39]$.

Power reduction and short analysis time are the main challenges for the GC component of portable GC-MS. Microchip-based GC has certainly demonstrated both reduced analysis time and reduced power consumption; however, it has proven difficult to evenly coat the separation channels and to connect them to injection systems and detectors, and their separation performance has not yet matched the high efficiency of conventional fused silica capillary columns [12]. Another approach has been to use low thermal mass GC that relies on resistively heating the capillary column instead of using a bulky convection oven [11, 14,
40-42]. Resistive heating provides high heating and cooling efficiency and speed. These qualities make low thermal mass GC ideal for fast analysis with minimum power consumption.

Two major challenges of any field analysis method is the collection and subsequent transfer of a sample to the analytical system. Many of the current CWA and TIC detectors rely on vapor detection. This is a problem for detection of less volatile CWAs and TICs, particularly at low environmental temperatures where vapor pressures of the target analytes are greatly reduced. Solidphase microextraction (SPME) offers a convenient method for sampling gaseous, liquid, and dissolved solid samples, concentrating the analytes, and transferring them to the injection port of a GC-MS. SPME theory, methodologies, and applications can be found elsewhere [43-45]. There are a number of reports that validate the use of SPME for the analysis of CWAs in air, water, and soil [46-51]. These studies include the analysis of hydrogen cyanide [46], VX [50, 52], sarin [48-50], soman [50], tabun [50], and mustard [51]. There have also been reports describing the detection of precursor chemicals and degradation products of CWAs using SPME [52-55].

In this report a new, portable GC-MS system is described, which is totally self-contained with carrier gas supply and battery power source. Sample introduction is performed using SPME with a low thermal mass GC injector for rapid desorption. Chromatographic separation is performed using a low thermal mass GC, and the mass analyzer consists of a miniature toroidal ion trap mass spectrometer (TMS). Embedded software performs data analysis during which TMS spectra are matched with on-board library spectra for positive identification of target compounds.

\section{Experimental}

\section{GC-TMS Instrumentation}

The portable GC-TMS system (Guardion-7, Torion Technologies, American Fork, UT, USA) consists of a low thermal mass injector, a low thermal mass GC, and a miniature toroidal ion trap mass analyzer. The entire system is a stand-alone instrument that can be used in the field without additional electrical power, gas supply, or equipment for data analysis and identification. The system is housed in a $47 \times 36 \times 18 \mathrm{~cm}(18.5 \times 14 \times$ 7 in.) Pelican case (Torrance, CA) and weighs about 13 $\mathrm{kg}(28 \mathrm{lb})$, including batteries (Figure 1a). The portable GC-TMS can be fully operated without an external computer system. A 6-in. liquid crystal display (LCD) allows real-time monitoring of the chromatogram and mass spectra. A graphical user interface (GUI) is used to navigate via three buttons between different options and windows that are displayed on the LCD. The GC-TMS system uses spectral deconvolution software (Ion Signature Technologies, North Smithfield, RI, USA) to enhance compound separation and identifica- 


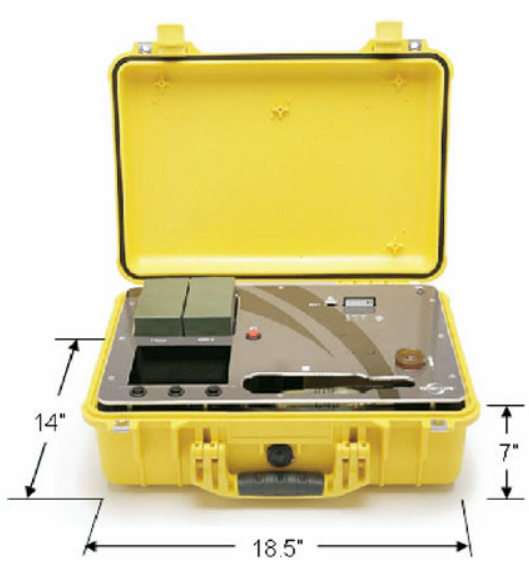

(a)

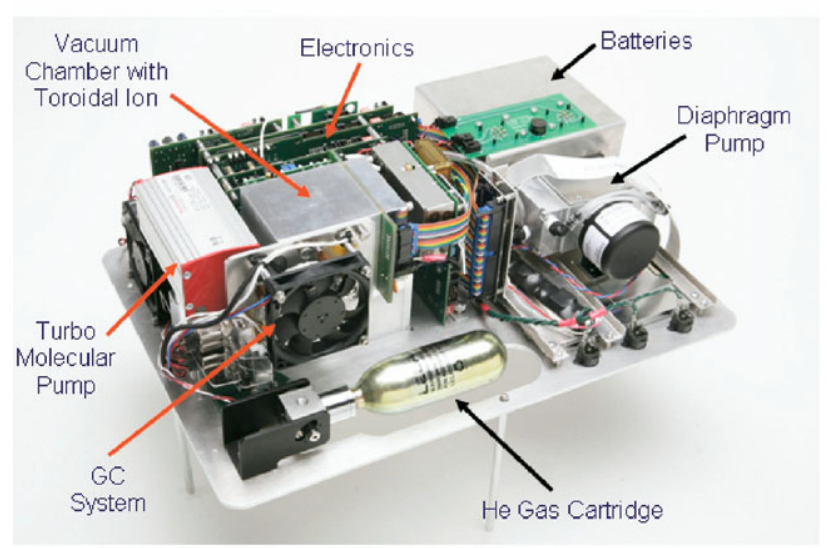

(b)

Figure 1. Photographs of the Guardion-7 GC-TMS showing (a) dimensions and (b) internal components.

tion [56]. The peak deconvolution algorithm improves the identification of poorly resolved GC peaks and obscure trace components. After completion of a run, accumulated data are deconvolved, and compounds that are detected and identified are displayed in tabular format on the LCD screen. Further data analysis can also be performed using a laptop via Ethernet connection or after downloading data from a flash memory card.

A $90-\mathrm{cm}^{3}$ disposable helium (He) cartridge provides the carrier gas to the GC-TMS system (Figure 1b). Cartridges are pressurized to 2500 psig, providing enough helium for about 100 analyses at a constant 25 psig column head pressure. The design of the GC-TMS instrument allows for easy access and replacement of the helium cartridges and batteries.

The peak power requirement of the GC-TMS is $80 \mathrm{~W}$ when all heaters (injection port, column, and transfer line) are utilized during the chromatographic analysis. This power is supplied by two non-rechargeable $24 \mathrm{~V}, 7.5 \mathrm{Ah}$ lithium/sulfur dioxide $\left(\mathrm{LiSO}_{2}\right)$ BA 5590 military-approved batteries, which allows roughly 50 consecutive analyses before the batteries must be replaced. The system could be modified for lithium ion rechargeable batteries
(BB 2590) by changing the instrument power supply design. An AC-to-DC $24 \mathrm{~V}$ power converter can be used when $110 \mathrm{~V}$ AC is available. The GC-TMS start-up time from power-on to ready state for injection is about $3 \mathrm{~min}$, and the total sample anaylsis turnaround time is $5 \mathrm{~min}$, including time for column cool-down.

\section{Mass Analyzer}

The miniature toroidal radio frequency (RF) ion trap mass analyzer has been previously described by Lammert et al. [27]. Figure 2a and b show photographs of the toroidal ion trap and Figure $2 \mathrm{c}$ shows a crosssectional drawing of the TMS, which includes the electron-gun assembly, trapping region, and the detector assembly. The toroidal trapping region has a radius $\left(\mathrm{r}_{\mathrm{o}}\right)$ of $2 \mathrm{~mm}$ and provides a storage capacity similar to a conventional cylindrical ion trap of $r_{o}=10 \mathrm{~mm}$. A nominal RF trapping frequency of $3 \mathrm{MHz}$ is used with a trapping amplitude of about $800 \mathrm{~V}_{\mathrm{p}-\mathrm{p}}$. During mass analysis, an ejection frequency sweep is applied to the filament end-cap to perform resonance ejection. This type of mass analysis provides better mass resolution than the traditional linear amplitude RF scan. Furthermore, simpler electronics are needed, in that the RF generator needs only a fixed-amplitude power supply. During the scanning period, the ejection frequency is scanned from ca. $1.4 \mathrm{MHz}$ to approximately $100 \mathrm{kHz}$ with about $5 \mathrm{~V}_{\mathrm{p}-\mathrm{p}}$ amplitude over the course of $60 \mathrm{~ms}$ (7500 Th/s) (see timing diagram, Figure 3). The electron gun produces a gated electron beam $(-70 \mathrm{eV})$ for ionization of analyte molecules. Ions are detected with a custom, continuous dynode electron multiplier detector (DeTech, Palmer, MA, USA) with an approximate gain of $10^{6}$ at $1300-1500 \mathrm{~V}$. The electron multiplier voltage is automatically set by monitoring the noise level during the first few seconds of each run. Ionization timing control is used to regulate the number of ions that are trapped, preventing overloading and ensuring optimal mass resolution. Ionization timing (Figure 3 ) is automatically controlled to values between 0.03 and $60 \mathrm{~ms}$. The number of ions in the trap is monitored for each $60-\mathrm{ms}$ scan and kept below a specified level by automatically adjusting the ionization time. Since ionization timing control is used, the sampling rate of the system varies from 8 to 16 scans/s, depending on the sample concentration. Work is in progress to increase the scan rate to allow for faster separations and shorter analysis times.

\section{Vacuum System}

The GC-TMS pumping system consists of a miniature dual-stage diaphragm roughing pump and a miniature turbo-molecular pump (Figure 1b). The roughing pump is a two-stage diaphragm pump (Model PU1781-N84.08.05, KNF Neuberger, Trenton, NJ, USA) and the turbomolecular drag pump has a pumping capacity of 11 $\mathrm{L} / \mathrm{s}$, a rotation speed of 90,000 rpm, and can achieve 


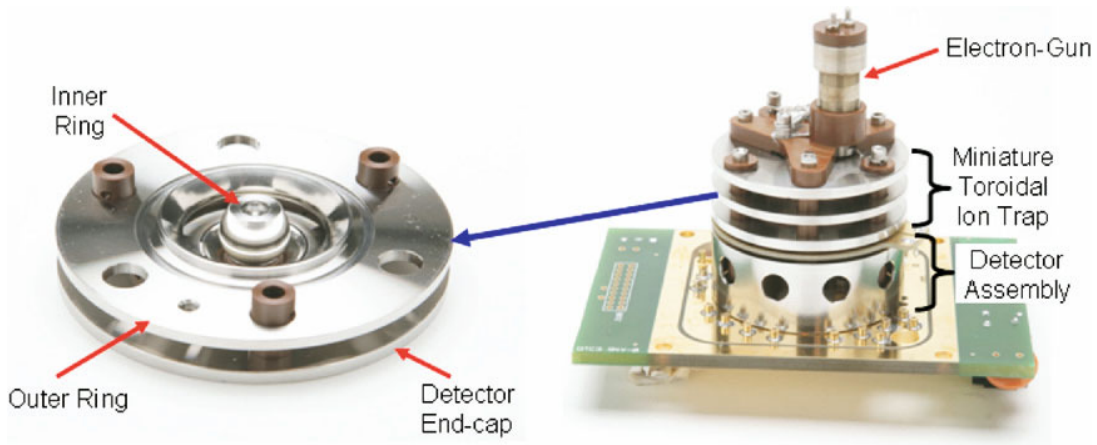

A

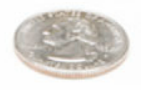

B

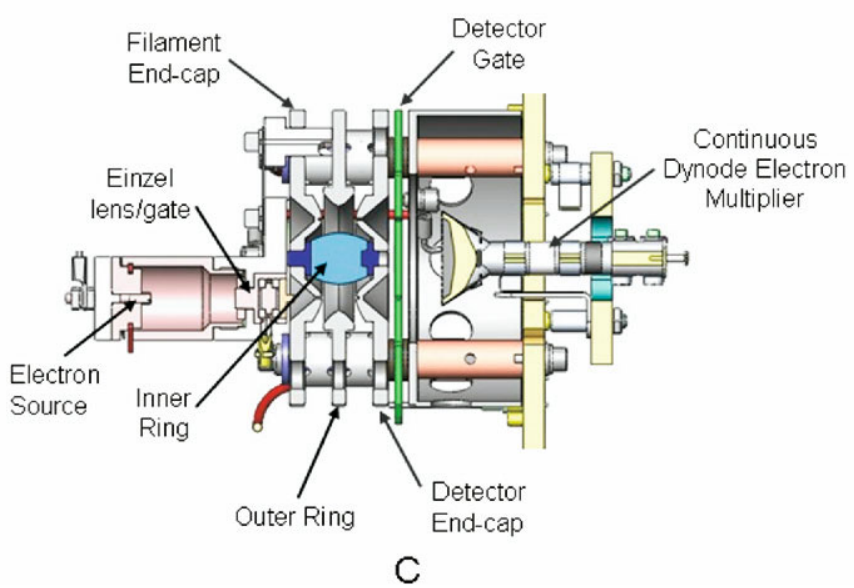

Figure 2. Miniature toroidal ion trap mass spectrometer. (a) Photograph of ion trap electrodes with top end-cap removed to show the ion storage region. (b) Photograph of ion trap stack and detector board assembly. (c) Cross-sectional diagram of toroidal ion trap mass analyzer showing major components. The end of the GC column (not shown) is placed between the filament end-cap and outer ring of the toroidal ion trap assembly.

pressures below $5 \times 10^{-4}$ torr (Model TPD 011, Pfeiffer Vacuum, Nashua, NH, USA). The assembled vacuum system can achieve pressures below $1 \times 10^{-3}$ Torr in 2 min with a $0.5 \mathrm{~cm}^{3} / \mathrm{min}$ of helium flow through the GC column.

\section{Low Thermal Mass GC}

The low thermal mass GC column assembly is fabricated by RVM Scientific (Santa Barbara, CA, USA) from a $5 \mathrm{~m} \times 0.1 \mathrm{~mm}$ i.d. $\times 0.4 \mu \mathrm{m} \mathrm{d}_{\mathrm{f}}$ MXT- 5 column (Restek, Bellefonte, PA, USA). Various columns can be used depending on user applications. The column is bundled with a resistive heating wire and thermocouples for temperature control. A small box fan is used for column cool-down (Figure 1b). This GC assembly is mounted on a fixture and connected to the low thermal mass injector and to the TMS through a transfer line. Under typical temperature programming conditions, the initial temperature $\left(40^{\circ} \mathrm{C}\right)$ is held for $10 \mathrm{~s}$ before it ramps to a final temperature of $250{ }^{\circ} \mathrm{C}$ at a ramp rate of $120^{\circ} \mathrm{C} /$ $\mathrm{min}$. The low thermal mass injector and transfer line are kept at $270{ }^{\circ} \mathrm{C}$. Helium is used as the mobile phase with a flow rate of $0.4 \mathrm{~mL} / \mathrm{min}$ at $100{ }^{\circ} \mathrm{C}$.

\section{SPME and SPME Holder}

SPME is an excellent solvent-free extraction method that combines extraction and concentration into a single step for the analysis of gases and liquid samples [57]. These features make SPME a convenient sampling method for on-site analysis. Because the GC-TMS system is designed for use in the field, a new SPME holder was developed to be easily operated with one hand while wearing bulky personal protective equipment. Figure 4, shows photographs of the new SPME holder. The push-button trigger (similar to the mechanism common to ballpoint pens) on top of the syringe enables the SPME fiber (65 $\mu \mathrm{m}$ PDMS-DVB, Supelco, Bellefonte, PA, USA) to be extended from or withdrawn into a protective metal needle after sampling and while being inserted into the injection port of the GC-TMS. The SPME holder has a weight of $34.7 \mathrm{~g}(1.22 \mathrm{oz})$ and a length of 18.5 $\mathrm{cm}$ (7.2 in.) when the fiber is retracted. The active sample 


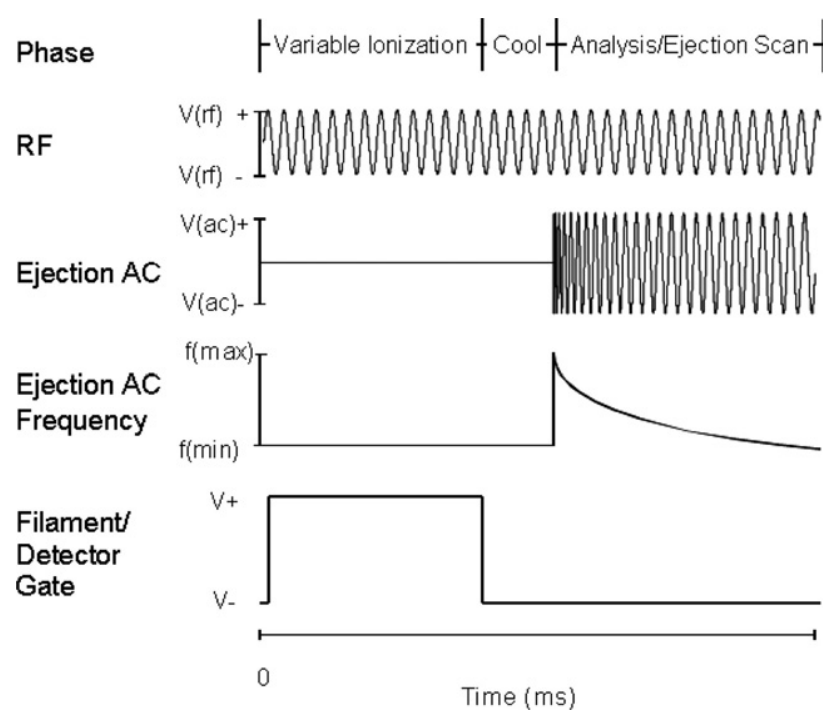

Figure 3. Timing diagram for the toroidal ion trap. The ejection frequency decreases with time according to $1 / \mathrm{f}$ to linearize the $\mathrm{m} / \mathrm{z}$ scale; the filament gate is variable from 60.0 to $0.03 \mathrm{~ms}$ to control ionization; and the maximum ionization time is indicated.

collection surface of the SPME fiber is 1-2 $\mathrm{cm}$ long and is coated with a 7 - to $100-\mu \mathrm{m}$ polymer film. Previous studies have indicated that polydimethylsiloxane-divinylbenzene (PDMS-DVB) is the preferred commercially available SPME coating for CWAs [46-55]. The GC temperature program and data acquisition automatically start when the SPME holder contacts the injection port. The SPME holder contains a miniature electronic board with a microchip that has the potential for receiving and storing sample related metadata.

\section{Low Thermal Mass Injector}

The resistively heated split/splitless injector was specifically designed for SPME with a low volume to minimize band broadening during injection [58-60]. The custom-made injector was constructed from 0.31 $\mathrm{mm}$ i.d. stainless steel tubing wrapped with Nichrome 80 heating wire (Pelican Wire, Naples, FL, USA). No liner was utilized in the design because SPME allows sampling of dirty matrices with minimal contamination of the injection system. However, possible adsorption of analytes was reduced by Sulfinert treatment (Restek) of the injector. If the injector does become contaminated, the injector assembly can be removed and cleaned. Because of its low thermal mass, the injector can be heated from room temperature to $270{ }^{\circ} \mathrm{C}$ in less than 3 min using less than $9 \mathrm{~W}$ of power and consuming only $6 \mathrm{~W}$ to maintain operating temperature. The use of Merlin Microseal septa (Restek) allows up to 2500 injections before replacement of a septum. For this work, splitless injections were performed by opening the split valve between 0.5 and $7 \mathrm{~s}$ after injection. The split ratio is nominally 20:1 when the split valve is open. The injector is also equipped with a septum purge that is typically operated at $1.0 \mathrm{~mL} / \mathrm{min}$ continuous flow rate.

\section{Data Analysis}

Quantitative deconvolution software (Ion Signature) is used for target compound identification. This software is embedded in the operating system of the GC-TMS. It uses both retention times and key mass spectral data to identify compounds. The data collected by the GC-TMS system are processed in near real time and matched against characteristic retention times and ion abundances for target analytes that are preloaded into the internal compound library. Identified compounds are listed on the LCD screen, along with hazard classification and match confidence level shortly after completing the analytical run.

\section{Chemicals and Standards}

All chemicals used were commercially available. Diethylphthalate $(99.5 \%), n$-butylbenzene $(99+\%)$, and 2chloroacetophenone (98\%) were obtained from SigmaAldrich (Milwaukee, WI, USA). Benzene (HPLC grade) was obtained from Spectrum Chemicals and Laboratory Equipment (Gardena, CA, USA). Toluene (HPLC grade) and methyl salicylate $(99 \%)$ were purchased from Fisher Scientific (Fairlawn, NJ, USA). Decafluorotriphenylphosphine (DFTPP) was obtained from Supelco, and naphthalene (Baker Analyzed Grade) was obtained from JT Baker (Phillipsburg, NJ, USA). The 624 EPA volatile halocarbon mix $(2000 \mu \mathrm{g} / \mathrm{mL}$ in methanol) was obtained from Restek. Disposable $90 \mathrm{~cm}^{3}$ high-purity helium cartridges were custom packaged by Leland (South Plainfield, NJ, USA).

\section{Sampling Methodology}

Sample solutions were placed in 15 - to $20-\mathrm{mL}$ vials with septum caps. The SPME needle was pushed through the septum in the vial cap and the SPME fiber was exposed to either the solution or head space. The exposure period was $30 \mathrm{~s}$ and $5 \mathrm{~min}$ for liquid and head space sampling, respectively, at room temperature with vial agitation. The SPME exposure time was chosen to simulate realistic field sampling protocols. The sample

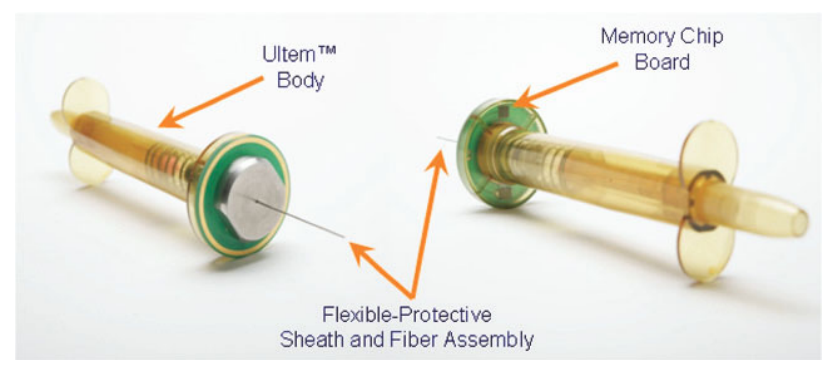

Figure 4. Photograph of SPME fiber holder syringe with memory chip for metadata storage. 
was desorbed from the SPME fiber for about $8 \mathrm{~s}$ at $270{ }^{\circ} \mathrm{C}$ after insertion of the SPME needle into the injection port of the GC-TMS.

\section{Results and Discussion}

\section{Mass Calibration}

Routine mass calibration is performed automatically by the GC-TMS by introducing a standard mixture of compounds with known GC retention order and fragment peak abundances. Any compound can be used for mass calibration as long as retention time and selected $\mathrm{m} / \mathrm{z}$ values are provided. During mass analysis, an ejection frequency is applied so that masses are scanned from 35 to $535 \mathrm{~m} / \mathrm{z}$. To calibrate the mass scale for the acquired data, a scan index is used. The scan index is obtained by dividing the electron multiplier signal during the mass analysis scan (60 ms) into 4000 discrete indices (15 $\mu \mathrm{s}$ each). The signal for each $15-\mu$ s scan is summed and stored in the appropriate index. The automated mass calibration algorithm software looks for mass fragment peaks at the retention time specified and assigns a scan index to the mass. A linear plot of the $m / z$ versus scan index is then used as the mass calibration for the instrument [61]. A seven-component mixture consisting of benzene, toluene, $n$-butylbenzene, naphthalene, 2-chloroacetophenone, diethylphthalate, and decafluo- rotriphenylphosphene in water (10 ppm each) was used in this work for calibration. After sampling for $30 \mathrm{~s}$, compounds were thermally desorbed into the GC-TMS injector. The ions selected for automatic calibration were $m / z 78$ from benzene, $m / z 65$ and 91 from toluene, $m / z 105$ from 2-chloroacetophenone, $m / z 128$ from naphthalene, $m / z 134$ from $n$-butylbenzene, and $m / z 149,177$, 222 from diethylphthalate, and $m / z 275$ and 442 from decafluorotriphenylphosphine. An automated mass calibration plot using this mixture can be seen in Figure S.1 in the Supplementary Information, which can be found in the electronic version of this article. A least linear squares curve fit provided an $R^{2}$ value of 0.99994 for a mass range of 65 to $442 \mathrm{~m} / \mathrm{z}$. Automatic mass calibration is simple to perform and allows the GC-TMS instrument to be rapidly and frequently calibrated to ensure mass accuracy during field measurements.

\section{Mass Spectral Resolution}

Toluene, dibromochloromethane, and diethylphthalate were used to determine the mass spectral resolution of the TMS. Samples of these compounds were prepared at the same concentration and sampled using the same procedure as previously described for automatic mass calibration. The mass spectral resolution of the GC-TMS instrument at full-width half-maximum (FWHM) was
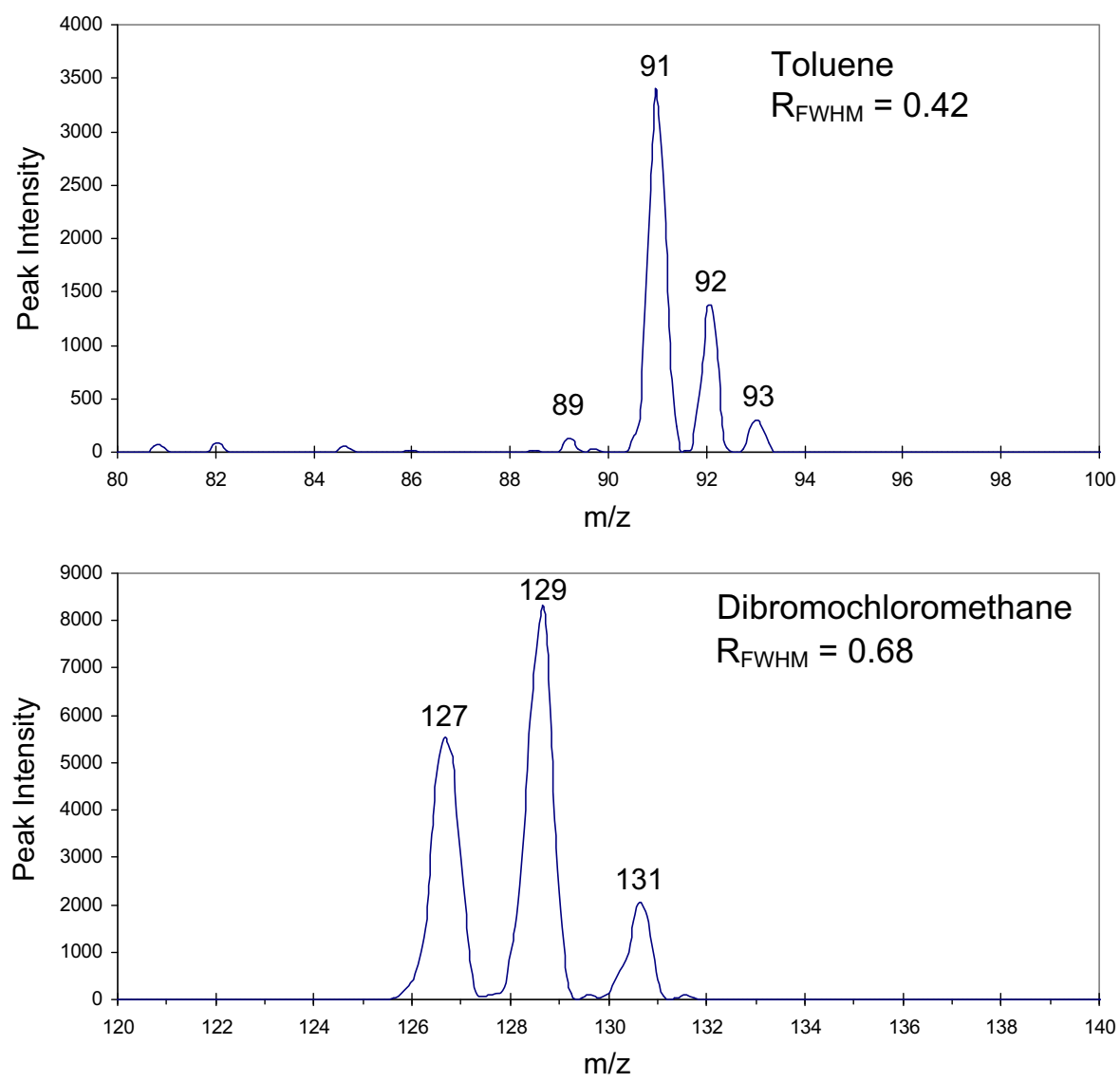

Figure 5. Mass spectra showing resolution of toluene and dibromochloromethane ions. 
$0.42,0.68$, and 0.80 for toluene $(m / z=91)$, dibromochloromethane $(\mathrm{m} / \mathrm{z}=127)$, and diethylphthalate $(\mathrm{m} / \mathrm{z}=$ $222)$, respectively. Spectra for toluene and dibromochloromethane are shown in Figure 5. The fragment ions and isotope ratios in these spectra are in close agreement with theoretical (isotope ratios) and library reference values. Better than unit mass resolution was obtained for the $m / z$ range from $<100$ to $>200$, which is comparable to the resolution achieved by most benchtop MS systems.

\section{Detection Limits}

GC-TMS detection limits were determined from both direct liquid injection and SPME headspace sampling. Direct liquid injections of chemical agent simulants (di- $n$-butylsulfide and methyl salicylate) were performed to determine the minimum quantity of compound introduced into the GC column that could be detected. Ethanol solutions with concentrations from 1.6 to $1600 \mathrm{ppm}$ were prepared. Direct liquid injections of $0.1 \mu \mathrm{L}$ were performed using a $0.5 \mu \mathrm{L}$ SGE syringe (Austin, TX, USA). Detection limits corresponding to a total ion signal intensity that was $3 \sigma$ above the background uncertainty from blank replicates were found to be 200 and 300 pg for methyl salicylate and di- $n$ - butylsulfide, respectively. A linear response was observed for concentrations ranging from 0.2 to $160 \mathrm{ng}$ with an $R^{2}$ value of 0.995 for di- $n$-butylsulfide (Figure S.2 in the Supplementary Information).

Headspace sampling was performed to determine the method detection limits. A four-compound mixture (benzene, toluene, n-butylbenzene, and naphthalene) was used, and aqueous solutions ranging in concentration from 0.1 to $100 \mathrm{ppb}$ were prepared. A 15-mL aliquot of each solution was placed in $20-\mathrm{mL}$ vials with septum caps. Headspace SPME sampling was performed for $5 \mathrm{~min}$ and then desorbed in the GC injector. The method detection limits were $0.1 \mathrm{ppb}$ for $n$-butylbenzene and naphthalene, $1 \mathrm{ppb}$ for toluene, and $10 \mathrm{ppb}$ for benzene.

\section{Analysis of Chemical Warfare Agents}

CWAs are substances that are intended for military purposes to be lethal, seriously injure, or incapacitate target individuals because of their physiological effects. Spectra were obtained using the GC-TMS for research development test and evaluation standards $(50 \mu \mathrm{g} / \mathrm{mL}$ each in isopropanol) of the nerve agents sarin (GB), soman (GD), cyclosarin (GF), and VX, as well as the blister agent mustard (HD). Figure 6 shows mass spec-
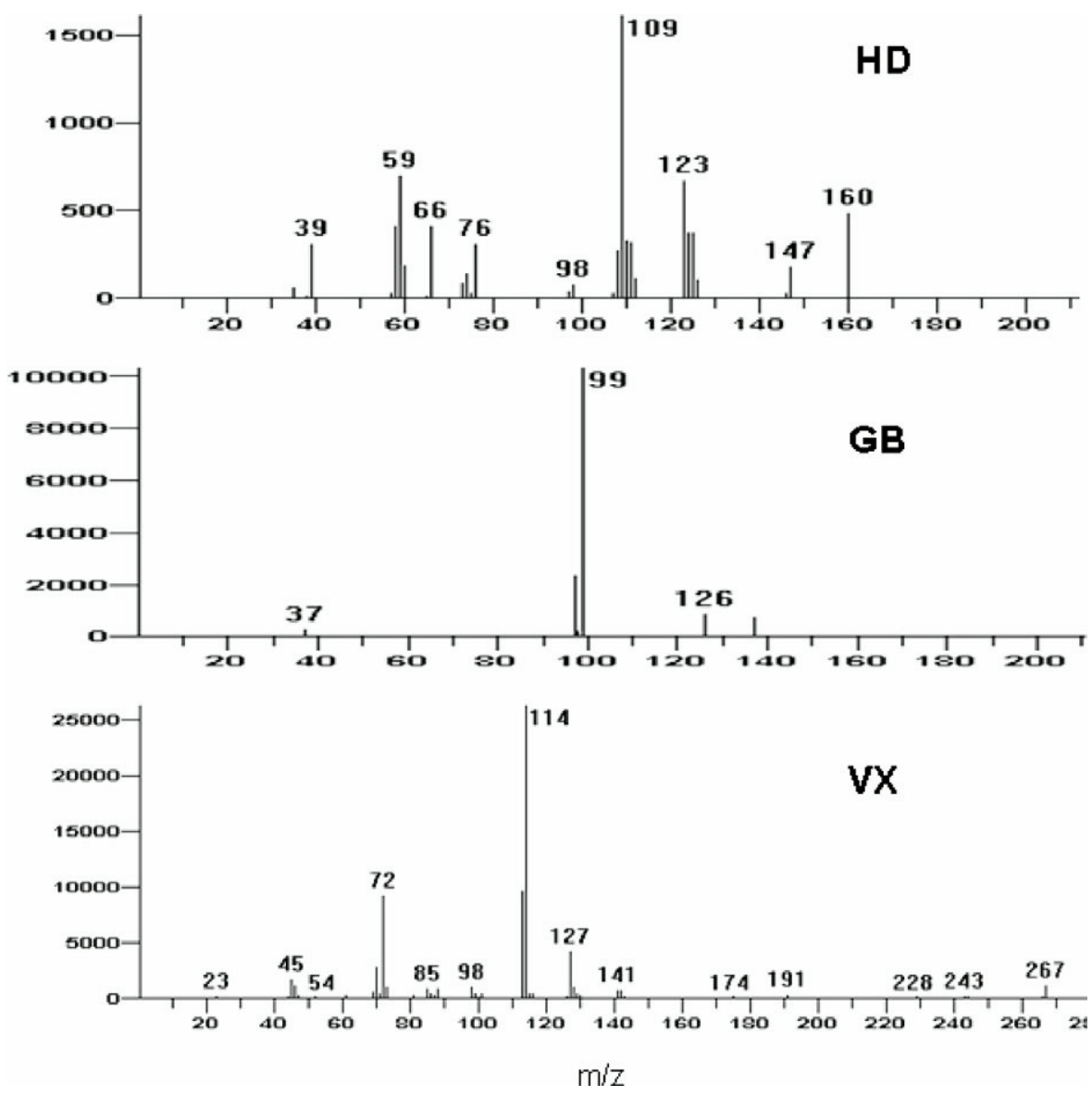

Figure 6. Mass spectra of HD blister agent and GB and VX nerve agents. 
tra for HD, GB, and VX. The ion fragments in these spectra are in close agreement with theoretical and library reference values. These analyses demonstrate the capability of the portable GC-TMS instrument for the detection of CWAs.

\section{Analysis of EPA Method 624 Volatile Halocarbon Compounds}

EPA Method 624 is used for the chemical analysis and determination of volatile organic compounds in municipal and industrial wastewater [62]. A standard mixture of the EPA Method 624 volatile halocarbon compounds was diluted to $20 \mathrm{ppm}$ in water, and SPME sampling was performed as previously described. Separation of the mixture was achieved in $<65$ s (Figure 7). Compounds that are not completely resolved chromatographically can be resolved and identified using the deconvolution software described in the experimental section. Examples of spectra for tetrachloroethene and bromoform are given in Figure 7. This separation shows the ability of the portable GC-TMS system to rapidly separate and identify organic compounds in complex mixtures.

\section{Conclusions}

The field-portable GC-TMS system described herein performs automatic linear mass calibration, achieves better than unit mass resolution for the mass range up to $220 \mathrm{~m} / \mathrm{z}$, and provides good chromatographic resolution of complex volatile organic samples. The system is truly portable with a weight of $13 \mathrm{~kg}$, battery power, on-board carrier gas supply, and full operation without an external computer. The instrument detection limits were determined to be in the low picogram range (200 pg for methyl salicylate). The method detection limit for headspace sampling using SPME was 100 ppt for aqueous solutions of $n$-butylbenzene and naphthalene. The embedded software, target compound library, and sampling methods are constantly being enhanced to address an expanding range of threat agents, hazardous compounds, environmental contaminants, and other target compounds of interest. The analytical performance of the portable GC-TMS approaches that of conventional bench-top GC-ion trap mass spectrometers. Portability, simple operation, and high performance make the GC-TMS instrument a valuable tool for field applications.

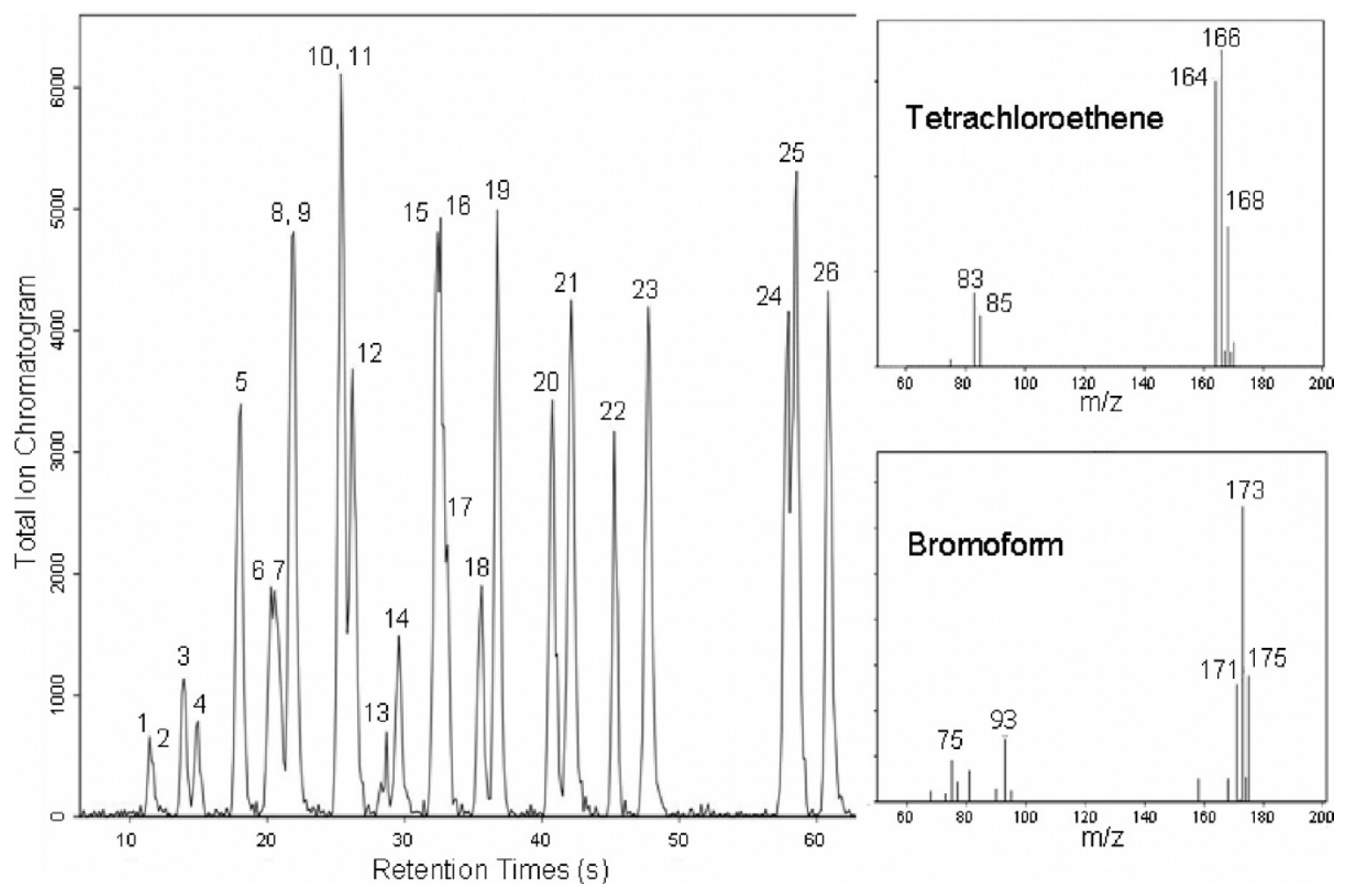

Figure 7. Total ion chromatogram of a 26 component EPA Method 624 volatile halocarbon compound mixture (20 ppm in water) with mass spectral inserts for tetrachloroethene (peak 19) and bromoform (peak 22). GC temperature program: $40^{\circ} \mathrm{C}$ for $10 \mathrm{~s}$, then $120^{\circ} \mathrm{C} / \mathrm{min}$ to $250{ }^{\circ} \mathrm{C}$ and hold for $10 \mathrm{~s}$. Peak identifications: (1) 1,1-dichloroethane, (2) methylene chloride, (3) trans-1,2dichloroethene, (4) 1,1-dichloroethane, (5) chloroform, (6) 1,2-dichloroethane, (7) 1,1,1-trichloroethene, (8) benzene, (9) carbon tetrachloride, (10) 1,2-dichloropropane, (11) trichloroethylene, (12) bromodichloromethane, (13) 2-chloroethylvinyl ether, (14) cis-1,3-dichloropropene, (15) trans-1,3-dichloropropene, (16) toluene, (17) 1,1,2-trichloroethene, (18) dibromochloromethane, (19) tetrachloroethene, (20) chlorobenzene, (21) ethyl benzene, (22) bromoform, (23) 1,1,2,2-tetrachloroethane, (24) 1,3-dichlorobenzene, (25) 1,4-dichlorobenzene, (26) 1,2-dichlorobenzene. 


\section{Acknowledgments}

The@uthors@ratefully@cknowledge@inancial@upport@rom@he

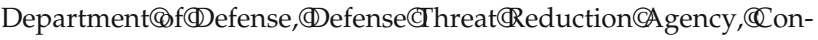
tract@o.(DTRA01-03-C-0047.

\section{References}

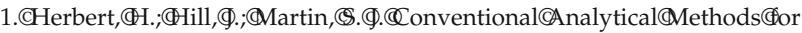
Chemical@Warfare@Agents.@ure Appl. Chem. 2002, 74, 2281-2291.

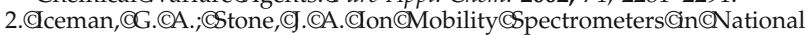
Defense.CAnal. Chem. 2004, 76, 391A-397A.

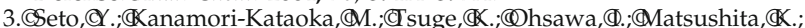

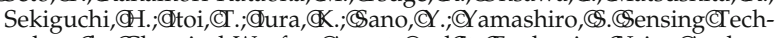
nologyథor@hemical-Warfare@gents@nd $₫$ ts $₫$ valuation@sing@uthenticCAgents.CSens. Actuators B 2005, 108, 193-197.

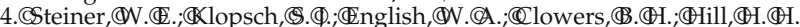
Detection@f@@hemical@Warfare@Agent@simulant@n@Various@Aerosol Matrixes@by@lon@Mobility@Time-of-Flight@Mass@Spectrometry.@Anal. Chem. 2005, 77, 4792-4799.

5.@Smith,@W.@D.@Analytical@Chemistry@at@the@Forefront $@$ of $@ H$ Homeland Defense.(A) nal. Chem. 2002, 74, 462A-466AA.

6.CArnold,CN.CS.;CDworzanski, (C).CP.;CSheya, CS.CA.;CMcCleannen, CW.CH.

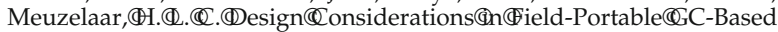
Hyphenated@nstrumentation.థield Anal. Chem. Tech. 2000, 4, $219 \oplus 238$.

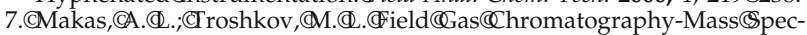
trometryథor@rast@Analysis.థ. Chromatoor. B 2004, 800, 55-(61.

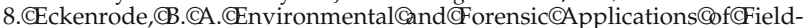
Portable@GC-MS:CAn@overview.đ. Am. Soc. Mass Spectrom. 2001, 12, 683-693.

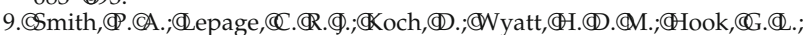

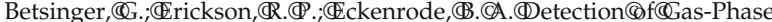
Chemical@Warfare@Agents@sing@ield-Portable@as@hromatography-

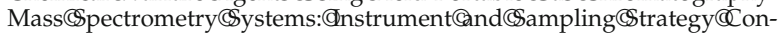
siderations. Crends Anal. Chem. 2004, 23, $296 \Subset 306$.

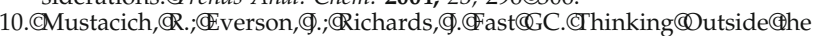
Box.@Am. Lab. 2003, 27, 38@41.

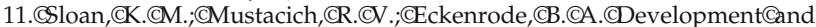
Evaluation@of@a@Low@Thermal@Mass@Fast@Chromatograph@for@Rapid Forensic@C-MS@Analyses.థield Anal. Chem. Tech. 2001, 5, $288 @ 301$.

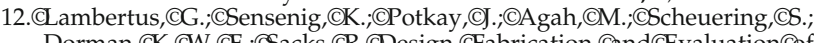
Dorman,CK.CW.CF.;CSacks, CR.CDesign, CFabrication, Cand@Evaluation@of Microfabricated@olumnsథr@eras@hromatography.@Anal. Chem. 2004, $76,2629 \Subset 2637$

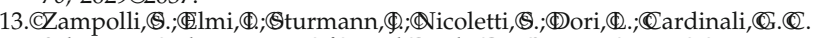
Selectivity@nhancement@f@etal@xide@ras@ensors@sing@@icromachined@Gas@Chromatographic@Column.@Sens. Actuators B 2005, 105, $400 @ 406$.

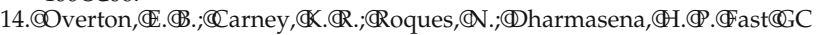
Instrumentation@nd@Analysisథor®ield@Applications.థield. Anal. Chem. Tech. 2001, 5, 97-105.

15.CSyage,@(CA.;CHanning-Lee,CM.CA.;CHanold,CK.CA.CA@Man@Portable, Photoionization@Time-of-Flight@Mass@ Tech. 2000, 4, 204@215.

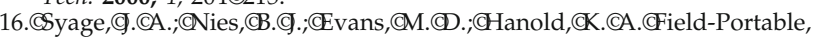
High-Speed@C/TOFMS.థ. Am. Soc. Mass Spectrom. 2001, 12, 648@655.

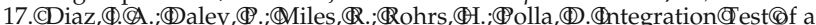
Miniature@ExB@Mass@Spectrometer@with@a@Gas@Chromatograph@for Development@of@a@Low-Cost,@Portable,@Chemical-Detection@System. Trends Anal. Chem. 2004, 23, 314@321.

18. Microsaic(Systems.@www.microsaic.com.

19.@Diaz,@.@A.;@Giese,@C.CF.; CGentry,CW.@R.@Portable@Double-Focusing Mass-Spectrometer(System@or@ield@as@Monitoring.®ield Anal. Chem. Tech. 2001, 5, 155-167.

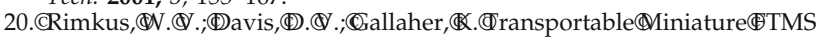
for@nalysis@f@orrosives@nd@hemical@Varfare@gents.@nథroceedings of the 4 th Workshop on Harsh-Environment MS,\$t.థetersburg®each, $₫ \mathrm{~L}$, 2003.

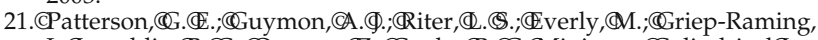

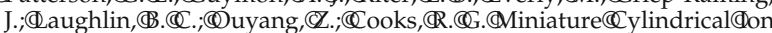
Traps@Mass(\$pectrometer.@Anal. Chem. 2002, 74, 6145-@153.

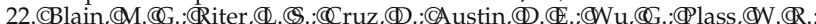
Cooks,@R.CG.CTowards@the@Hand-Held@Mass@Spectrometer:@Design Considerations, (Simulation, @andథrabrication@f@icrometer-Scaled@ylindricalథonđraps.థnt. J. Mass Spectrom. 2004, 236, 91-104.

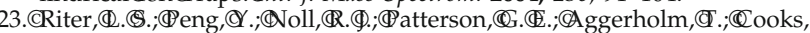
R.@.CAnalyticalథerformance@f@QMiniature@ylindricalథon@rap@Mass Spectrometer.@Anal. Chem. 2002, 74, 6154@(6162

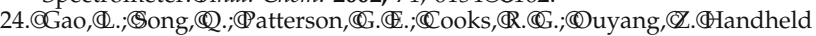
RectilinearđonđTrap@Mass@spectrometer.CAnal. Chem. 2006, 78, 5994@ 6002.

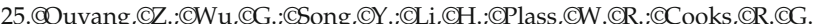
Rectilinearđon@Trap:@ Concepts, $@$ Calculations, Cand@Analytical@Performance@f@@ew@Mass@Analyzer.@Anal. Chem. 2004, 76, 4595-(4605.

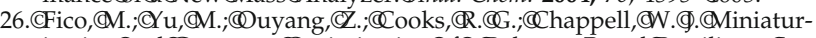
ization@nd@eometry@ptimization@f@olymer-Basedबrectilinearđon Trap.@Anal. Chem. 2007, 79, 8076@8082.C

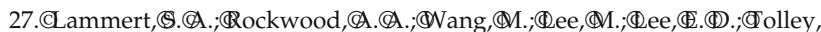

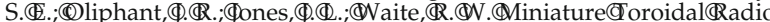
Frequencyథonđrap@Mass@Analyzer.థ. Am. Soc. Mass Spectrom. 2006, 17 $916 \Subset 922$.

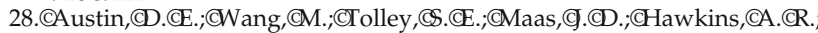

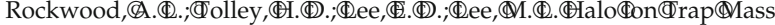
Spectrometer. CAnal. Chem. 2007, 79, 2927-2932.

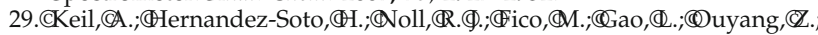

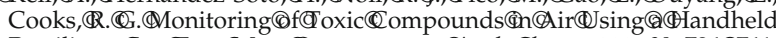
Rectilinear@on@rap@Mass@sectrometer.@Anal. Chem. 2008, 80, 734@741.

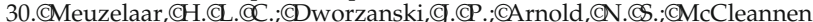
W.CH.CAdvancesđin@Field-Portable@Mobile@GC/MS@instrumentation. Field Anal. Chem. Tech. 2000, 4, 3-13.

31.CTorion@Technologies,@Guardion-7@Hand-portable@GC-TMS@System. http://www.torion.net/.

32.@riffin@Analytical.@ttp:/ / www.griffinanalytical.com/griffin400.html.

33. CDaltronics, CB.CEnhanced@Environmental@Mass@Spectrometer@(Eª). http://www.bdal.de/cbrn-detection/chemical-detection/e2m.html.

34.CEckenrode,CB.CA.CThe@Application@of(Can@integrated@Multifunctional Field-Portable@C/MS\&ystem. Field Anal. Chem. Tech. 1998, 2, 3-20.

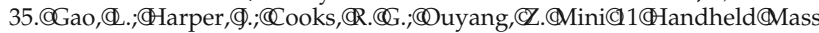

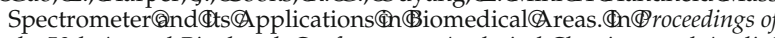
the 59th Annual Pittsburgh Conference on Analytical Chemistry and Applied Spectroscopy, (New@rleans, $(A$, A March@-(6,(2008.

36. Inficon(C) HAPSITEC Smart( Identification(C) System.(C) http:/ / www . inficonchemicalidentificationsystems.com/en/hapsitechemicalidentification. html

37. Smith, P. A.; Sng, M. T.; Eckenrode, B. A.; Leow, S. Y.; Koch, D.; Erickson, R. P.; Lepage, C. R. J.; Hook, G. L. Towards Smaller and Faster Gas Chromatography-Mass Spectrometry Systems for Field Chemical Detection. J. Chromatogr. A. 2005, 1067, 285-294.

38. Bier, M. E.; Cooks, R. G. Membrane Interface for Selective Introduction of Volatile Compounds Directly into the Ionization Chamber of a Mass Spectrometer. Anal. Chem. 1987, 59, 597-601.

39. Lammert, S. A.; Plass, W. R.; Thompson, C. V.; Wise, M. B. Design, Optimization and Initial Performance of a Toroidal rf Ion Trap Mass Spectrometer. Int. J. Mass Spectrom. 2001, 212, 25-40.

40. MacDonald, S. J.; Wheeler, D. Fast Temperature Programming by Resistive Heating with Conventional GCs. Am. Lab. 1998, 30, 27-28, 37-38, 40 .

41. Jain, V.; Phillips, J. B. Fast Temperature Programming on Fused-Silica Open Tubular Capillary Columns by Direct Resistive Heating. J. Chromatogr. Sci. 1995, 33, 55-59.

42. Stearns, S. D.; Cai, H.; Koehn, J. A.; Brisbin, M.; Cowles, C.; Bishop, C Direct Resistively Heated Columns for Fast and Portable Gas Chromatography. In Proceedings of the 59th Annual Pittsburgh Conference on Analytical Chemistry and Applied Spectroscopy, New Orleans, LA, March 1-6, 2008.

43. Zhang, Z.; Yang, M. J.; Pawliszyn, J. Solid Phase Microextraction. Anal. Chem. 1994, 66, 844A-853A.

44. Alpendurada, M. d. F. Solid-Phase Microextraction: A Promising Technique for Sample Preparation in Environmental Analysis. J. Chromatogr. A 2000, 889, 3-14.

45. Pawliszyn, J. Application of Solid Phase Microextraction. Royal Society of Chemistry: Letchworth, Hertfordshire, UK, 1999; p 655.

46. Smith, P. A.; Sheely, M. V.; Kluchinsky, T. A. J. Solid Phase Microextraction with Analysis by Gas Chromatography to Determine Short Term Hydrogen Cyanide Concentrations in a Field Setting. J. Sep. Sci. 2002, 25, 917-921.

47. Hook, G. L.; Kimm, G.; Betsinger, G.; Savage, P. B.; Swift, A.; Logan, T. Smith, P. A. Solid Phase Microextraction Sampling and Gas Chromatography/Mass Spectrometry for Field Detection of the Chemical Warfare Agent O-Ethyl S-(2-diisopropylaminoethyl) Methylphosphonothiolate (VX). J. Sep. Sci. 2003, 26, 1091-1096.

48. Harvey, S. D.; Nelson, D. A.; Wright, B. W.; Grate, J. W. Selective Stationary Phase for Solid-Phase Microextraction Analysis of Sarin (GB). J. Chromatogr. A 2002, 954, 217-225.

49. Schneider, J. F.; Boparai, A. S.; Reed, L. L. Screening for Sarin in Air and Water by Solid-Phase Microextraction-Gas Chromatography-Mass Spectrometry. J. Chromatogr. Sci. 2001, 39, 420-424.

50. Lakso, H.-A.; Ng, W. F. Determination of Chemical Warfare Agents in Natural Water Samples by Solid-Phase Microextraction. Anal. Chem. 1997, 69, 1866-1872.

51. Kimm, G. L.; Hook, G. L.; Smith, P. A. Application of Headspace Solid-Phase Microextraction and Gas Chromatography-Mass Spectrometry for Detection of the Chemical Warfare Agent Bis(2-chloroethyl) sulfide in Soil. J. Chromatogr. A 2002, 971, 185-191.

52. Hook, G. L.; Kimm, G. L.; Koch, D.; Savage, P. B.; Bangwei, D.; Smith, P. A. Detection of VX Contamination in Soil Through Solid-Phase Microextraction Sampling and Gas Chromatography/Mass Spectrometry of the VX Degradation Product Bis(diisopropylaminoethyl)disulfide. J. Chromatogr. A 2003, 992, 1-9.

53. Rearden, P.; Harrington, P. B. Rapid Screening of Precursor and Degradation Products of Chemical Warfare Agents in Soil by SolidPhase Microextraction Ion Mobility Spectrometry (SPME-IMS). Anal. Chim. Acta 2005, 545, 13-20.

54. Szostek, B.; Aldstadt, J. H. Determination of Organoarsenicals in the Environment by Solid-Phase Microextraction-Gas ChromatographyMass Spectrometry. J. Chromatogr. A 1998, 807, 253-263. 
55.@Woten,థ.@.;Ashley,Ф.@.;@alafat,@A.@.@uantitation@f@-Chlorovinylarsonous@Acid@n@Human@urine@y@Automated@solid-Phase Microextraction-Gas@Chromatography-Mass@spectrometry.@. Chromatogr. B 2002, 772, 147-153.

56.đU.,S.®PA.đnnovations in Site Characterization;@PA-542-R-98-006;@ffice of(Solid@Vaste@nd®mergency $₫$ Response:@Vashington,(DC,(September, 1998;@) 48.

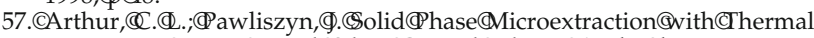
DesorptionđUsingđFused@Silica@Optical@Fibers.CAnal. Chem. 1990, 62, 2145-2148.

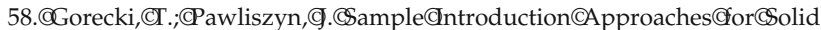
Phase@Microextractionđapid@C.CAnal. Chem. 1995, 67, 3265-3274.

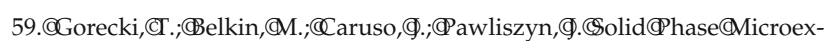
traction@s@Sample@ntroductionđechniqueథroradio®requency@low Discharge@Mass@(\$pectrometry.@Anal. Commun.@997,(\$44,(275-277.

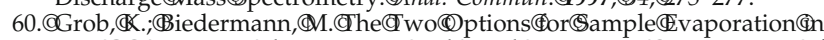
Hot@C@njectors: $₫$ hermospray@and@andథrmation@ptimization@f Conditions@and@njector(Design.(Anal. Chem. 2002, 74, $10 \oplus 16$

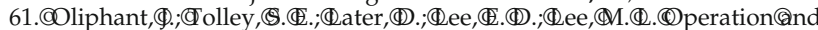
Design@hallenges@or@ $₫$ Hand-Portable@C/TMS.@n@roceedings of the 56th Annual American Society for Mass Spectrometry Conference on Mass Spectrometry, Denver, CO, June 1-5, 2008

62. U.S. EPA. Methods for Organic Chemical Analysis of Municipal and Industrial@Vastewater@Method(624-Purgeables).๑http://www.epa.gov/. 